ISSN 1112-9867

http://www.jfas.info

\title{
PASSIVE AIR CONDITIONING METHODS FOR DIFFERENT CLIMATES, SPECIAL FOCOUS ON IRAN
}

\author{
N. Maftouni ${ }^{1, *}$ and A. Bagheri ${ }^{2}$ \\ ${ }^{1}$ Faculty member at Mechanical Enginering group, Faculty of Engineering, Alzahra \\ University, Tehran, Iran \\ ${ }^{2}$ MSc Student at Mechanical Enginering group, Faculty of Engineering, Alzahra University, \\ Tehran, Iran
}

Published online: 05 June 2016

\begin{abstract}
One of the most important parameters to be considered in life's style and life's situations of human is the comfort. The usual tools for making thermal comfort are traditional mechanical air conditioners. The disadvantage of them is using much energy and also being dangerous for environment ecological system. Therefore passive air conditioning can be used as a good alternative to conventional system. There are many various ways to achieve this goal. There should be a deep attention to the climate of each region to study passive air conditioning there. In this research different approaches for some major climates are discussed. There is a special focus on Iran's climates and new ideas are presented for passive air conditioning in some of them. Results show that passive approach is an advisable proposed solution in Iran.
\end{abstract}

Keywords: passive air conditioning; climate; energy.

Author Correspondence, e-mail: n.maftouni@alzahra.ac.ir,nmaftouni@gmail.com doi: http://dx.doi.org/10.4314/jfas.8vi2s.19 


\section{INTRODUCTION}

It looks like that the development of science and technology in today's world has made the chance of better conditions for human life. This development would lead to new difficulties such as the excessive use of fossil fuels. Global energy consumption has risen rapidly too, and it is expected to grow more [1]. Much use can lead to serious environmental problems such as air pollution which is one of the most important disadvantages of fossil fuels. Though the fossil fuels meet the energy and fuel needs, still it's a high time to look forward for the alternative renewable sources of energy such as wind turbines, solar panels, tidal generators, biomass and compost. The environmental impact associated with its usage together with the depletion of fossil fuels, which account for $80 \%$ of primary energy sources [2], has drawn the attention to energy conservation.

Building thermal conditioning systems provides a vast scope for energy conservation [3]. The chief goal of building is to provide a healthy and comfortable place; therefore energy saving cannot come at the expense of this. Thermal comfort improves concentration, craftsmanship and ardor [4] enhancing productivity and quality [5], whereas a poor thermal environment results in sickness [6], [7]. Therefore a good alternative to mechanical air conditioning is essential.

Passive air conditioning if employed properly is an excellent alternative, which provides a comfortable and healthy environment. Various passive approaches options are available such as nocturnal radiation, geothermal, ventilation, evaporative, hydro geothermal, Deep Ocean, thermal insulation and shading along with their advantages, limitations, working principles and climatic dependence. Passive techniques should be studied in various climatic regions. A full understanding of local climate is the main requirement for the designs of climate responsive architecture towards sustainable development. Under hot humid climate, naturally ventilated buildings are very common and thus occupant's comfort criteria may differ significantly [8].

This paper proposes new ideas by which the potential of comfort improvement, by using passive air conditioning strategies, could be derived. Moreover, it compares how these techniques can improve the energy performance of passive air conditioned buildings at 
different climates especially in Iran. Five climatic regions; warm humid summer, mild winter; hot dry summer, cool winter; mild temperate; warm temperate and cool temperature climate are investigated in the world and also in Iran as case studies.

\section{PASSIVE COOLING METHODS IN DIFFERENT CLIMTES IN THE WORLD}

There are many climates that according to conditions of Iran here five of them are considered that look like major ones. They are as follow:

a) Warm humid summer, mild winter; b) Hot dry summer, cool winter; c) Warm temperate; d) Mild temperate and e) Cool temperate.

Researches show that in each of these climates there are some advises to have a reliable passive cooled air condition building. Figure 1 shows a well naturally air conditioned house. Situations of above different climates are presented here respectively (Bouchair and Downton, 2013)[9].

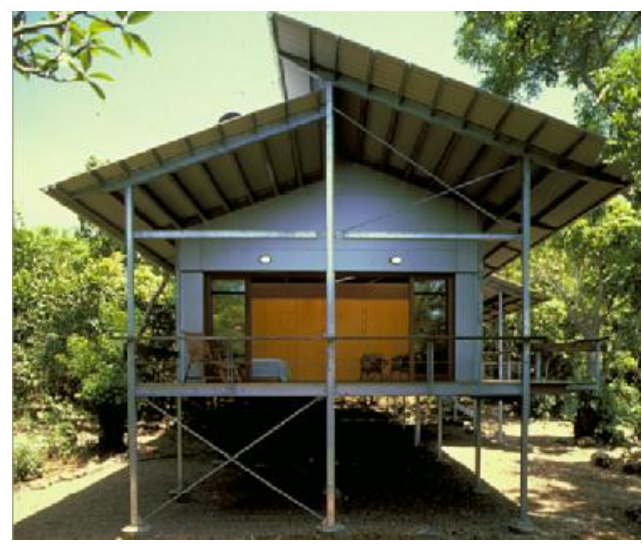

Fig.1. A well naturally ventilated house (Bouchair and Downton, 2013) [9]

\section{a- Warm Humid Summer, Mild Winter}

As design considerations the following points should be mentioned. The design should always be sited for exposure to cooling breezes and design for cross-ventilation. Thinner plans and design openings to encourage movement of breezes through and within the building should be used. Night-time sleeping comfort is important in design. Screened and shaded outdoor living areas are proposed. Overuse of glazing is not suitable [8].

Low SHGC glazing is good candidate in all cases and low U-value glazing is good for regions 
with cooler winters or hotter summers. All east and west-facing walls are better to be shaded. South-facing walls north of the tropic of Capricorn should be shaded. Appropriate levels of passive shaded north-facing glass are to be used as heating requirements increase in more southerly and inland regions. $100 \%$ open able windows area such as louver or casement is suitable.

For insulation coming results are notable. In areas where no winter heating is required, multiple layers of reflective foil in ceiling/roof are usable to create a one-way valve effect. Internal wall surfaces from any external thermal mass are proposed to be insulated. Highly breathable reflective vapor barriers in walls and bulk insulation to rooms that are air conditioned are good options. Roof spaces are advised to be used to provide heat loss/gain buffer zones by ventilating them in summer and sealing them in winter with fans or 'smart' ventilators [10]

In direct heating and cooling following points should be mentioned. With good design it is unnecessary to use auxiliary heating. Ceiling fans are required in all living and sleeping spaces. Construction systems considerations are as coming. Where summer ground temperatures exceed $19{ }^{\circ} \mathrm{C}$ at $3 \mathrm{~m}$ depth, it is proposed to use elevated lightweight floors. Using earth coupled slabs in all areas where deep ground temperatures are less than $19^{\circ} \mathrm{C}$ in summer is suitable. Lightweight wall construction are advisable where day-night temperature ranges are low and add thermal mass as these ranges exceed $6^{\circ} \mathrm{C}$. Light colored roof and wall materials are favorite choices [11].

\section{b- Hot dry summer, cool winter}

Design considerations are as discussed below. High levels of well-insulated thermal mass are proposed. North-facing, high thermal mass living areas with passive solar access are suitable. It is advised to select a site exposed to cooling breezes, and design to exclude adverse winds while allowing for cross-ventilation and night purging. It should be considered to design to capture cool air drainage on still nights; cool air flows in similar patterns to water as surface temperatures drop due to night sky radiation. External wall area is to be limited. Compact floor plans with central, closable stack ventilation shafts or solar chimneys are proper options. Central courtyards with evaporative cooling water features to allow night cooling with wind 
protection are good ideas. It is reasonable to provide screened, shaded outdoor living areas that allow winter sun penetration. Garden ponds and water features outside windows are proposed to provide evaporative cooling [12].

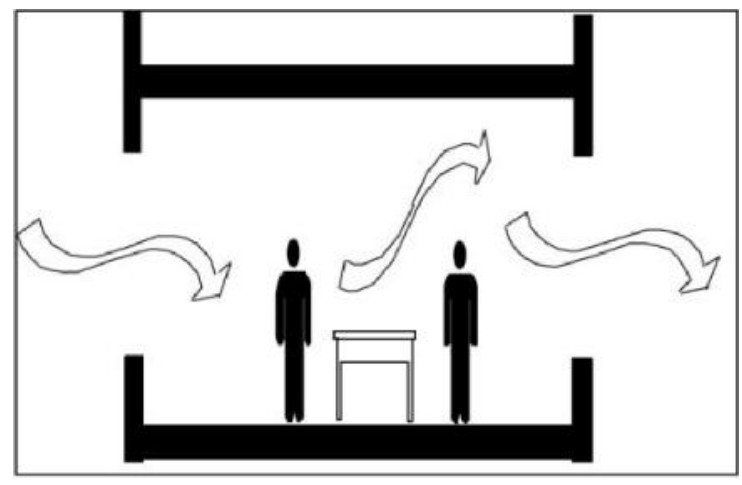

Fig.2. A schematic of cross ventilation [3]

In windows and shading part overuse of glazing should be avoided. Different glazing types for each facade are to be used; low U-value glazing is essential in all cases. Living areas and bedrooms should be double glazed. For north-facing windows high SHGC glazing and passive shading are suitable. For east and west facades low SHGC coatings are proper choices. South-facing glass should have low U-value and high visible light transmittance [13]. Thermally improved or insulated frames are important. Passive solar shading to northerly windows is critical. All east and west glass should be shaded in summer. Adjustable shading has to be considered to allow variable solar access in spring and autumn [14], [15].

In insulation part bulk and reflective insulation is proposed in ceilings, and bulk or reflective insulation is suitable in walls. External insulation should be provided to all thermal mass. Also xunder concrete slabs should be insulated if using in-slab heating. For heating and cooling evaporative cooling and passive solar heating in living areas are suitable. Ceiling fans in all living and sleeping spaces should be provided. For construction systems, high thermal mass construction is preferred. Also earth coupled slabs are suitable and light colored roof materials are proposed [16]. Figure 3 shows a traditional Iranian yard in Kashan city of Iran. 


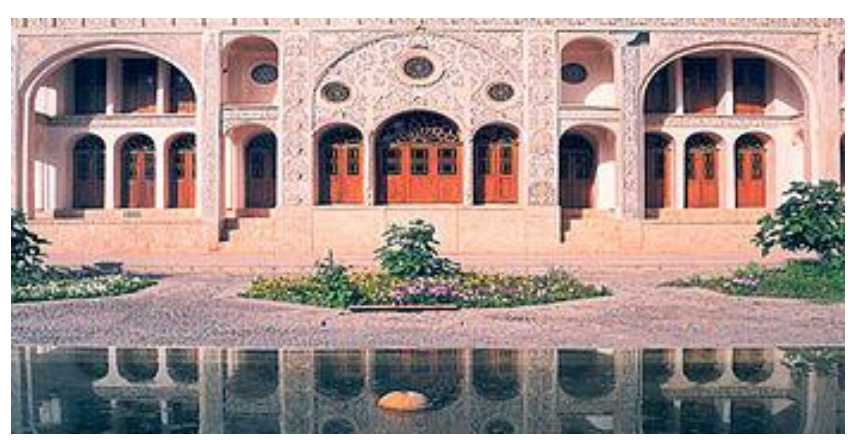

Fig.3. A traditional Iranian yard in Kashan

\section{c- Warm Temperate}

In design considerations individual site analysis is needed to identify conditions that call for specific design adjustments. In all subzones, passive solar heating and cooling are important. Different approaches are required for passive cooling depending on the patterns and reliability of cool breezes.

To reduce heat gain, inappropriate or overuse of glazing should be avoided. Passive solar heating is always desirable and simply achieved where access to adequate sunlight is available. Where solar access is not available, using lightweight building frames should be considered that respond quickly and efficiently to minimal, carbon efficient auxiliary heating. Lower thermal mass requirements are suitable because they allow for low embodied energy solutions. Roof spaces are to be used as a thermal buffer zone by ventilating them in summer and sealing them in winter. For better windows and shading overuse of glazing is not proper. Passive solar shading on northerly windows is required.

All east and west-facing glass have to be shaded in summer [17].

For insulation bulk and reflective insulation is good in ceilings, and bulk or reflective insulation is suitable in walls. No auxiliary cooling is required. Ceiling fans are required in all living and sleeping spaces. In construction systems earth coupled slabs are highly beneficial. Low embodied energy walls, roofing and finishes should be used. Composite thermal mass construction is ideal. Light colored roof materials are proposed also in this case.

\section{d- Mild Temperate}

Reducing heat gain though appropriate use of windows and glazing; is a critical design 
consideration.

Cooling comfort is simply achieved with adequate cross-ventilation and minimizing solar and ambient heat gains with shading and insulation. External wall areas, especially east and westfacing; should be minimized. Convective ventilation and heat circulation should be used. Lower thermal mass requirements allow for low embodied energy solutions. Sites with solar access require north-facing living areas with majority of glazing. Where solar access is unavailable, lightweight solutions that respond quickly and efficiently to minimal, carbonefficient auxiliary heating are a viable alternative.

Roof spaces create a thermal buffer zone to summer heat gain (ventilated) and winter heat loss.

Overuse of glazing should be avoided. Size and orientation of windows should be designed carefully, as this will often yield ideal results with less expensive glazing options. High SHGC and low U-value glazing are suitable. All east and west-facing glass should be shaded in summer. Here also adjustable shading has to be considered to allow variable solar access in spring and autumn [18].

For insulation bulk and reflective insulation is good in ceilings, and bulk or reflective insulation is suitable in walls. Under concrete slabs should be insulated in the case of using in-slab heating. No auxiliary heating or cooling should be required. Ceiling fans should be included in all living and sleeping spaces. Earth coupled slabs maintain comfortable summer temperatures that can easily be raised by passive solar heating in winter.

For construction systems earth coupled slabs are highly beneficial here also. High thermal mass walls can be used if within glass to mass ratios. Low embodied energy walls, roofing and finishes should be chosen.

\section{e- Cool Temperate}

Best passive solar design principles should be applied where access to sunlight permits. High glass to mass ratios should be used. Climate change has to be considered when choosing type, location and quantity of thermal mass. The use of north-facing walls and passively shaded glazing should be maximized. External wall areas, especially east and west should be 
minimized. Cross-ventilation and night-time cooling in are proposed summer. High ceilings should be avoided and airlocks between lower and upper floors should be provided. Controllable convective air movement throughout the house should be mentioned to distribute heat while minimizing draughts and temperature stratification. New homes must be sited with solar access, exposure to cooling breezes and protection from cold winds. Where passive solar access is unavailable, all glass areas should be minimized and thermal mass has to be limited except where exposed to heating sources. Roof spaces must be ventilated in summer and be sealed in winter. Carbon efficient auxiliary heating should be installed. Passive solar shading to northerly windows is essential. All east and west-facing glass in should be shaded summer. Using adjustable shading to some west-facing glass areas has to be considered to boost afternoon solar heat gains in winter and allow variable solar access in spring and autumn.

Bulk insulation is usable in walls, ceilings and exposed floors. Heavy drapes with sealed pelmets are proposed to insulate glass in winter. For walls bulk insulation with highly breathable sarking or multiple layers of reflective foil insulation, are required with detailed design to ensure condensation discharge. Airlocks must be provided to entries. Even 10 star homes in the more extreme regions of these climates might require some auxiliary heating for psychological comfort. Lower rated homes will require heating. High level passive or active solar heating is highly desirable where available. Wood heating, although it is carbon neutral, has negative health and biodiversity impacts and should be avoided in built-up areas. Wellpositioned, adequately heated thermal mass will provide sufficient thermal comfort in bedrooms. Cooling is unnecessary with good cross or closable ventilation and ceiling fans in living and sleeping spaces.

In construction systems here also earth coupled slabs are beneficial except where $3 \mathrm{~m}$ earth temperatures are below $16^{\circ} \mathrm{C}$ in winter. Low thermal mass walls should be used on sites with no solar access. Lightweight wall construction has to be used where diurnal temperature ranges are low.

\section{PASSIVE AIR CONDITIONING METHODS IN MAJOR CLIMATES IN IRAN}

The experienced passive methods in Iran are discussed here and also some new ideas are 
represented for some climates of this country. Table 1 represents the regions in Iran where each climate exists and also the main characteristics of them.

Table 1. Five studied climates in Iran

\section{Climate}

a) Warm humid summer, mild winter

\section{Main characteristics}

\section{Related regions in Iran}

Persian gulf and Oman sea

coastal regions

summers with mild winters moderate to low diurnal (day-night)

temperature range, which can vary significantly between regions.

Central regions and central Distinct wet and dry seasons. Low rainfall and low to moderate

b) Hot dry summer, cool winter desert humidity. No extreme cold but can be cool in winter Hot to very hot summers common.

c) Warm temperate Khazar sea coastal regions
Moderate diurnal (day- night) temperature range. Four distinct seasons: summer and winter can exceed human comfort range; spring and autumn are ideal for human comfort. Mild winters with low humidity. Hot to very hot summers with low to moderate humidity. Widely variable solar access and cooling breeze directions and patterns.

d) Mild temperate Mountain regions and Alborz and Zagros hillsides. and winter exceed human comfort range; spring and autumn are ideal for human comfort. Mild to cool winters with low humidity. Hot to very hot summers, moderate humidity.

e) Cool temperate East Azerbaijan and Ardabil
Low humidity, high diurnal (day-night) temperature range. Four distinct seasons: summer and winter exceed human comfort range; highly variable spring and autumn conditions (range increasing with climate change). Cold to very cold winters with majority of rainfall (decreasing with climate change). Hot dry summers (increasing with climate change). 


\section{a- Warm Humid Summer, Mild Winter}

Regions around Persian Gulf and Oman Sea belong to this climate type. Summer temperature raises near $40 \mathrm{C}$ easily in summer and humidity also reaches to $70 \%$ in that season. Focusing on results of experiments all over the world in these parts of Iran the design should always be sited for exposure to cooling breezes and design for cross-ventilation. Thinner plans and design openings to encourage movement of breezes through and within the building should be used. Night-time sleeping comfort is important in design. Screened and shaded outdoor living areas are proposed. Overuse of glazing is not suitable [8].

\section{b- Hot Dry Summer, Cool Winter}

In these regions in Iran, Kashan, Yazd, Kerman and some other parts wind catchers, also called wind towers have been used since many years ago. Wind catchers can save the electrical energy used to provide thermal comfort during the warm months of the year, especially during the peak hours. Wind towers are installed on top of the buildings, in the direction of the maximum wind speed in the region. If the desired wind speed is accessible in several directions, additional wind towers can be installed in several positions [13]. Wind tower can also rotate and set itself in the direction of the maximum wind speed. In the regions where the wind speed is low, to improve the efficiency of the system a solar chimney or a one-sided wind tower can be installed in another part of the building in the opposite direction. Using transparent materials in the manufacturing of the proposed wind towers improves the use of natural light inside the building. The major advantage of wind towers is that they are passive systems requiring no energy for operation. Also, wind towers reduce electrical energy consumption and environmental pollution [12]. 


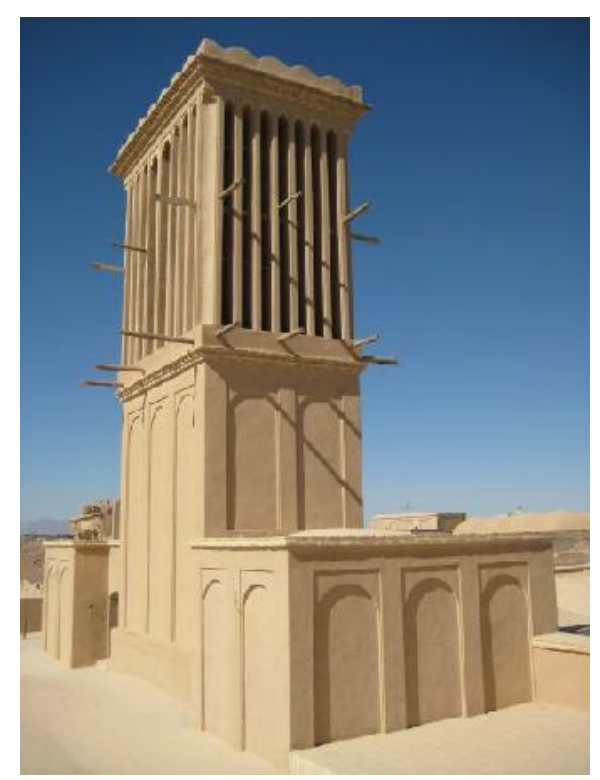

Fig.4. A wind catcher in Yazd, Iran

The passive cooling effects of a courtyard of a small building also have been studied [19]. The passive cooling features considered in one of these researches have been the shading effects of courtyard walls and trees planted next to the south wall of the building, the presence of a pool, a lawn and flowers in the yard, and the wind shading effects of the walls and trees. Results show that these features alone cannot maintain thermal comfort during the hot summer hours in hot dry areas, but reduce the cooling energy requirements of the building to some extent. They have an adverse effect of increasing the heating energy requirements of the building slightly. The same savings in cooling energy needs of the building can be obtained through many features such as wall and roof insulation, double-glazed windows, Persian Blinds, and special sealing tapes to reduce infiltration. They all save on heating energy requirements as well [14].

\section{c- Warm Temperate}

Coastal regions of Khazar Sea are considered having this climate. The efforts should be done to reduce heat. To reduce heat gain, inappropriate or overuse of glazing should be avoided. Passive solar heating is always desirable and simply achieved where access to adequate sunlight is available. Where solar access is not available, using lightweight building frames should be considered that respond quickly and efficiently to minimal, carbon efficient 
auxiliary heating. All east and west-facing glass have to be shaded in summer [17].

For insulation bulk and reflective insulation is good in ceilings, and bulk or reflective insulation is suitable in walls. Under concrete slabs should be insulated if using in-slab heating. External insulation should be provided to all thermal mass. No auxiliary cooling is required. Ceiling fans are required in all living and sleeping spaces. In construction systems earth coupled slabs are highly beneficial. Low embodied energy walls, roofing and finishes should be used. Composite thermal mass construction is ideal. Light colored roof materials are proposed also in this case.

\section{d- Mild Temperate}

Hillsides of Alborz and Zagros mountains are included in this climate type. Some ideas can be done to use passive air conditioning in this climate. Reducing heat gain with appropriate use of windows and glazing is a critical design consideration.

Cooling comfort is simply achieved with adequate cross-ventilation and minimizing solar and ambient heat gains with shading and insulation. External wall areas, especially east and westfacing; should be minimized. Convective ventilation and heat circulation should be used. Lower thermal mass requirements allow for low embodied energy solutions. Sites with solar access require north-facing living areas with majority of glazing. Where solar access is unavailable, lightweight solutions that respond quickly and efficiently to minimal, carbonefficient auxiliary heating are a viable alternative.

Roof spaces create a thermal buffer zone to summer heat gain (ventilated) and winter heat loss. Overuse of glazing should be avoided. Size and orientation of windows should be designed carefully, as this will often yield ideal results with less expensive glazing options. High SHGC and low U-value glazing are suitable. Always snug fitting drapes with pelmets should be used. Passive solar shading is to be used on northerly windows. All east and westfacing glass should be shaded in summer. Here also adjustable shading has to be considered to allow variable solar access in spring and autumn [18]. 


\section{e- Cool Temperate}

The major parts of Iran that have this climate are East Azerbaijan and Ardabil. Some ideas may be proposed to best use of energy in this climate regarding the research works derived in the world. Best passive solar design principles should be applied. High glass to mass ratios should be used. The use of north-facing walls and passively shaded glazing should be maximized. Living areas are to be located on the north, bedrooms and service areas must be on the south. External wall areas, especially east and west should be minimized. Crossventilation and night-time cooling in are proposed summer. High ceilings should be avoided and airlocks between lower and upper floors should be provided. Controllable convective air movement throughout the house should be mentioned to distribute heat while minimizing draughts and temperature stratification. New homes must be sited with solar access, exposure to cooling breezes and protection from cold winds. Where passive solar access is unavailable, all glass areas should be minimized and thermal mass has to be limited except where exposed to heating sources. Roof spaces must be ventilated in summer and be sealed in winter. Careful sizing and orientation of windows is essential. All east and west-facing glass in should be shaded summer. Using adjustable shading to some west-facing glass areas has to be considered to boost afternoon solar heat gains in winter and allow variable solar access in spring and autumn. Bulk insulation is usable in walls, ceilings and exposed floors. Heavy drapes with sealed pelmets are proposed to insulate glass in winter [9].

\section{CONCLUSION}

It is obvious that one of the most important parameters to be considered in air conditioning is the human comfort. The traditional mechanical air conditioners are the conventional tools for making thermal comfort. The disadvantage of them is using much energy and also being dangerous for environment ecological system. So passive air conditioning; can be used as a good alternative. Different approaches for some major climates were discussed. There was a special focus on Iran's climates and new ideas were presented for passive air conditioning in some of them. Results show that passive approach is an advisable proposed solution in Iran and can be classified as follow. 
-Passive air conditioning systems are viable alternatives to energy intensive mechanical systems.

-Various modeling procedures are available to study the performance and design of passive systems.

-Passive conditioning systems are ecologically friendly and results in comfortable environment.

-It should be considered passive AC systems are dynamic and their performance differs with time of day and seasons, excepted Deep Ocean cooling.

-Designing of passive AC systems is dependent on the characteristics of the site.

\section{REFERENCES}

[1] Lombard LP. A review on buildings energy consumption information. Energy Building. 2008, 40. 394-398.

[2] IEA. Key world energy statistics, International Energy Agency, 2014.

[3] Kolokotsa D. A road map towards intelligent net zero- and positive-energy buildings, Sol Energy. 2011, 85, 3067-3084.

[4] Zhao J. Productivity model in hot and humid environment based on heat tolerance time analysis. Build Environment. 2009, 44.2202e7.

[5] Srinavin, K. and Mohamed, S. Thermal environment and construction workers' productivity: some evidence from Thailand. Build Environment. 2003, 38, 339-345.

[6] Balaras C. A. Indoor thermal conditions in hospital operation rooms. Energy Building, 2007, 39, 454-470.

[7] Wolkoff, P. and Kjaergaard, S.K. The dichotomy of relative humidity on indoor air quality, Environ Int. 2007, 33. 850-857.

[8] Chyee Toe, D. et. al. Numerical Simulation of Passive Cooling Strategies for Urban Terraced Houses in Hot-Humid Climate of Malaysia. 30 th International Plea Conference. 2014, Ahmedabad, India.

[9] Bouchair, C. and Downton, P. Design for climate. Retrieved from Australian government, 2013, http://www.gov.au/. 
[10]Ben Cheikh, H. and Bouchair, A. Experimental studies of a passive cooling roof. Revue des Energies Renouvelables, 2008, 49, 515-522.

[11]Nguyen, A.T. and Reiter, S. A climate analysis tool for passive heating and cooling strategies in hot humid climate based on Typical Meteorological Year data sets. Energy and Buildings, 2014, 68, 756-763.

[12]Abedi, K, and Azami, A. Sustainability Analyses of Passive Cooling Systems in IranianTraditional Buildings approaching Wind-Catchers. Recent Advances in Energy, Environment and Development, 2014, 52, 521-543.

[13]Dehghani-sanij, A.R., et. al. A new design of wind tower for passive ventilation in buildings to reduce energy consumption in windy regions Renewable and Sustainable Energy Reviews, 2015, 42, 182-195.

[14]Foruzanmehr, A. People's perception of the loggia: A vernacular passive cooling systemin Iranian architecture .Sustainable Cities and Societ,. 2015, 50, 61-67.

[15]Bahadori, M., and Haghighati, F. Passive Cooling in Hot, Arid Regions in Developing Countries by Employing Temperature of Internal Surfaces. Building and Environment, 1985, 20(2), 103-113.

[16]Dokkar, B., et.al. Passive cooling of telecom shelter using solar chimney with Earth-air heat exchanger, Recent Advances in Energy, Environment, Biology and Ecology. 2014, $37,231-240$.

[17]Zinzi, M., and Agnoli, S. Cool and green roofs. An energy and comfort comparison between passive an active methods, Energy and Buildings, 2012, 45, 66-76.

[18]Wenzel, K. Low-energy buildings in southern and eastern Mediterranean countries. ECEEE, 2009, 52, 767-779.

[19] Safarzadeh, H. and Bahadori, M.N. Passive cooling effects of courtyards. Building and Environment, 2005, 40, 89-104.

\section{How to cite this article:}

Maftouni $\mathrm{N}$ and Bagheri A. Passive air conditioning methods for different climates, special focous on Iran. J. Fundam. Appl. Sci., 2016, 8(2S), 242-256. 